\title{
Polysemy in Context
}

\author{
Diana Movsisyan \\ Artsakh State University
}

$T^{t}$ is generally known that most words represent several concepts and thus possess

1 the corresponding number of meanings. A word having several meanings is called polysemantic, and the ability of words to have more than one meaning is described by the term polysemy. Polysemy is the association of two or more related senses with a single linguistic form (Taylor 1989:99).

I.V. Arnold states that polysemy is inherent in the very nature of words and concepts as every object and every notion has many features, and a concept reflected in a word always contains a generalization of several traits of the objects. Hence, the possibility of using the same name in secondary nomination for objects preserving common features which are sometimes only implied in the original meaning is called polysemy (Arnold 1986:41).

Polysemy is one of the most important issues of recent linguistic semantics, since the analysis of polysemy and polysemization processes is indispensable for accurate reading, language acquisition, computational linguistics and similar tasks. Although its importance was already recognized in the historical-philological tradition in early $20^{\text {th }}$ century and was emphasized again by S. Ullmann, it was not until recently that polysemy became a central issue in linguistic semantics.

The complex relations between meanings and words were first noted by the Stoics. "However, 'concrete research into the multiplicity of meaning only began in the $18^{\text {th }}$ century' and was continued in the $19^{\text {th }}$ century by linguists interested in meaning from the point of view of etymology, historical lexicography or historical semantics" (Nerlich 1992:351). The $19^{\text {th }}$ century linguist Bréal, whose research into polysemy marked a new starting point, shifted the study of polysemy away from lexicography and etymology and investigated polysemy as "synchronic pattern of meanings surrounding a word, which is itself the ever changing result of semantic change" (Cuyckens, Zawada 2001:85).

The issue of polysemy and the attendant practical task of word sense disambiguation (WSD) take on entirely new dimensions in context where a word might have innumerable possible meanings. Hence, the present paper aims at producing useful linguistic analysis of polysemantic words in context, in this way to show the indispensible role of the context for disambiguating polysemy.

Semantics began to attract the attention of Indo-European linguists towards the end of the $19^{\text {th }}$ century. The contextual method of linguistic research, with the meaning realized through what surrounds the word in actual speech is studied in the works of N.N. Amosova. In her work "English Contextology" she defines context as the minimal stretch of speech determining each individual meaning of the word in its immediate syntactical environment. Some linguists don't distinguish a speech situation (immediate extra-lingual circumstances under which the utterance takes place) from context. G.V. Kolshansky discriminates between linguistic and extra-linguistic context, defining context as the whole set of conditions under which a linguistic unit is used (Amosova 1968:106). 
The two more or less universally recognized main types of linguistic contexts which serve to determine individual meanings of words are the lexical context and the grammatical context. These types are differentiated depending on whether the lexical or the grammatical aspect is predominant in determining the meaning. In lexical contexts of primary importance are the groups of lexical items combined with the polysemantic word. When we want to describe the individual meaning of a polysemantic word, we find it sufficient to use this word in combination with some members of a certain lexical group. There is a view that if we know all the possible collocations (or word-groups) into which a polysemantic word can enter, we know all its meanings. Thus, the meanings of the adjective heavy, for instance, may be analyzed through its collocability with the words weight, safe, table, snow, wind, rain, industry, artillery. The meaning at the level of lexical contexts is sometimes described as a meaning by collocation (<mglukp.narod.ru/lexicology.doc:2>).

It is common knowledge that it is the context that prevents from any misunderstanding of meanings. For instance, the adjective $d u l l$, if used out of context, would mean different things to different people or nothing at all. It is only in combination with other words that it reveals its actual meaning: a dull pupil, a dull plague, a dull weather, etc. Sometimes, however, such a minimum context fails to reveal the meaning of the word and it may be correctly interpreted only through a second-degree context as in the following example: The man was large but his wife was even fatter. The word fatter here serves as a kind of indicator pointing that large describes a stout man and not a big one $(<$ http://cityref.ru/prosmotr/19537-0.htm:5 $>$ ). The semantic indicator is the element of the same syntactical unit which denotes the meaning. When indication comes from the lexical meaning of the indicator, it is a case of lexical context (Amosova 1968:108).

In the lexical context of the first degree there is a direct syntactical connection between the indicator and the dependent: He was arrested on a treason charge. In lexical context of the second degree there is no direct syntactical direction between the dependent and the indicator. For example in I move that Mr. Last addresses the meeting the dependent move is not directly connected to the indicating minimum addresses the meeting (Arnold 1986:57).

Roughly, the context may be subdivided into lexical, syntactical and mixed. Lexical meaning, for instance, determines the meaning of the word black. It denotes colour when used with the key-word naming some material or thing, e.g. black velvet, black gloves. When used with key-words denoting feeling or thought, it means sad, dismal, e.g. black thoughts, black despair. With nouns denoting time, the meaning is unhappy, full of hardships, e.g. black days, a black period (Arnold 1986:56).

The negative evaluative connotation of the adjective notorious is linked with the negative connotation of the nouns with which it is regularly associated: a notorious criminal, thief, gangster, gambler, gossip, liar, miser, etc. It is a common error to see a different meaning in every set of combinations. For instance, an angry man, an angry letter. Is the adjective angry used in the same meaning in both these contexts or in two different meanings? Some people will say "two" and argue that (man - name of person; letter - name of object) and, on the other hand, a letter cannot experience anger. True, it cannot; but it can very well convey the anger of the person who wrote it. As to the combi- 
nability, the main point is that a word can realize the same meaning in different sets of combinability ( $<$ mglukp.narod.ru/lexicology.doc:28>).

"Adjectives are notoriously hard to divide lexicographically into sense", says R. Moon (Moon 1987:86-87). "They are often heavily context-dependent and flexible, taking on as many meanings as you like or leave space for." The example she gives is light. This, she claims, has only "two main strands of meaning" (which nevertheless "interwine"): not heavy in weight and not intense or great in amount, degree, etc. But she goes on to list ten context groupings each requiring different wordings to explain their meaning: a light rain; a light blue shirt; the light breeze; a light sleep(er); her light voice; light lunch; a light white wine; light injuries; light housework and her light graceful step. Thus, although she claims only two true "senses", at least these ten usages would apparently need to be treated separately in a dictionary.

Dealing with verbal contexts we can consider linguistic factors: lexical groups of words, syntactic structure of the context and so on. There are cases, however, when the meaning of the word is ultimately determined not by these linguistic factors, but by the actual speech situation in which the word is used. The meanings of the noun ring in to give somebody a ring or of the verb get in I've got it are determined by actual speech situations. The noun ring in such a context may possess the meaning of a circlet of precious metal or a call on the telephone ( $<$ http://cityref.ru/prosmotr/19537-0.htm:6>).

D.A. Cruse argued that "the meaning of a word could be known by the company it keeps" (1986:72). A word's meaning is defined by the pattern of its contextualized associations with other words. "A sense spectrum should be thought of as having at least potentially many dimensions, and as continuously growing, amoeba-like". According to him "a single sense can be modified in an unlimited number of ways by different contexts, each context emphasizing certain semantic traits, and obscuring or suppressing others" (1986:52). Considering Cruise's example of handle, we can note that taking a traditional approach to WSD, the relevant dictionary sense of handle in phrases like handle of door or handle of sword could be: a part of an object which is specially made for holding or opening it (1), and a part which is designed to be held or operated with the hand (2).

However, the links between handle and words like sword and door produce very different sets of associations yielding a rich and detailed picture of the meaning of handle in each phrase. The links between handle/door, are much more varied, reflecting more about the functional role that door handles play. The overall weights for handle/sword are higher than those for handle/door. Finally, the core aspect of the relevant senses of handle - namely, that handles are used for holding and opening - are strongly weighed only in the case of handle/door. In the case of handle/sword Mind Net reflects a strong bias in favour of interpreting this pair as referring to the physical aspect of a sword, rather than the manner of its use. The word handle has 22 senses in Mind Net, most of them unrelated (e.g. the total amount of money bet on an event or over a set period of time) to either doors or swords. Yet the context provided by a two-word query - the crudest imaginable linguistic context - allowed us to focus on just salient portion of the enormous graph (Cruse 1986:53-54).

A search on the Web for a single polysemous keyword like line yields a huge set of 
hits reflecting every imaginable sense of this word. Begin adding context in the form of other keywords, however - insisting, say, that telephone and wire occur near line - and the set of hits suddenly becomes cohesive. Salton \& Buckley discuss this effect, showing how retrieval techniques that compare similarity vectors to find instance of words used in similar contexts effectively discriminate between word-senses (Salton \& Buckley 1991:1012-1015).

To illustrate the role of polysemy in context we will consider the sound complex light which is often used in speech of all functional styles and can appear to be a noun with different meanings, an adjective with a huge variety of meanings, or a polysemantic verb.

In the examples below, which were taken from solely the story "The Apple Tree" by John Galsworthy, the role of various types of context is observed without difficulty.

Watching his friend, lying there, with that smile, and the candle-light on his face, Ashurst shuddered.

(Galsworthy:21)

In this very example the word form light is a noun with the meaning the energy that makes us see things. As an ambiguous word the meaning of which can be understood through the context, it is the context dependant. The indicator is the structure the candle ... on his face. The indicator revealing a noun is the definite article on the left, the absence of any other noun immediately following light (in this case it would prove to be an adjective). The lexical meaning is clarified by the unit of lexical context of the first degree and is variable - the indicator may be replaced with some other words with the same general meaning without affecting the semantic content of the dependant: light of a torch, light of the sun, light of a lamp.

In a kind of intoxication he would watch the pint-white buds of some backward beech tree sprayed up in the sunlight against the deep blue sky.

(Galsworthy:9)

All day Ashurst rested his knee in a green painted wooden chair on the patch of grass by the yew-tree porch, where the sunlight distilled the scent of stocks and gillyflowers.

(Galsworthy:5)

The songs of the cuckoos and the blackbirds, the laughter of the yaffles, the level-slanting sunlight, the apple blossom had crowned her head.

(Galsworthy:10)

He lay there a long time, watching the sunlight wheel till the crab-trees threw shadows over the bluebells.

(Galsworthy:14) 
In the above mentioned examples we have illustrated the usage of the word sunlight in various lexical contexts. It is a monosemantic word, on the other hand sunlight is one of the meanings of the polysemantic word light possessing the meaning daylight, daybreak, the light of the sun.

\section{Prank of the moonlight! Nothing!}

(Galsworthy:4)

We have the meaning light from the sun received on the earth after reflection by the moon, illumination by the moon.

There was no longer light in any window.

(Galsworthy:22)

In this occurrence the word being considered is a noun with the meaning of the thing that produces light. The indicating minimum is the structure no longer ... in any window. The context clarifies that it is not an abstract notion, it can be moved physically.

The proper part of speech can be identified with the help of the verb. In actual speech the understanding of the meaning requires a chain of dependant-indicator pairs.

The context is variable:

A window of the hotel, high up, was lighted; he saw a shadow move across the blind.

(Galsworthy:22)

He took a candle, lighted it, and went to his bedroom, which was next to Hallidays.

(Galsworthy:21)

In these examples to light is used in the meaning to illuminate or cause to illuminate.

Another example is the following:

(1) On one side of the recessed fireplace sat two small boys, idle and good as gold; on the other sat a stout, light-eyed red-faced youth...

(Galsworthy:4)

(2) This red, blue-eyed, light-lashed, ton-haired face stuck as firmly in his memory as the girl's own face, so dewy and simple.

(Galsworthy:5)

In the first example light is an adjective indicating the colour of the eyes. The indicating complex is -eyed and -faced. The lexical meaning is clarified through the presence 
of the word eye or elements of the parts of the face and the description of an appearance. Consequently, the context can be considered variable. In example 2 light indicates brightness in colour.

The stars were bright in a very dark blue sky, and by their light some lilacs had that mysterious colour of flowers by night no one can describe.

(Galsworthy:22)

In this example there is a noun with the meaning the natural medium, natural radiation, that makes sight possible. The proper part of speech is recognized due to the presence of the nouns stars, sky, night.

[...] and began pacing up and down over the grass, a grey phantom coming to substance for a moment in the light of the lamp at either end.

(Galsworthy:22)

First of all, in this example the lexical homonymy should be eliminated: in the light of does not possess the meaning taking into account. The lexical meaning of the object (here an oil lamp in a container of metal and glass with a handle) assists us to state the meaning of the noun is anything that illuminates, such as a lamp or a candle.

And from staring at the framed brightening light Ashurst fell asleep.

(Galsworthy:5)

Here the indicating minimums are the participles framed and brightening. So, light indicates the meaning anything that lets in light, such as a window.

And away over there was the loom of the moor, and away and away the sky stars had not as yet full light, pricking white through the deep blue heavens.

(Galsworthy:5)

In this example light indicates the meaning the outcome of the action of giving light to something, the process of being guided with the light or brightness of countenance.

Thus, a word changes its meaning under various speech conditions, hence, it is imperative to use contextual indicators in the speech continuum to take away the ambiguity. Without minding the context, people would not understand each other, and the natural function of language - to carry out meaning - would not be fulfilled. Each context is seen to generate potentially indefinite range of meanings. The idea of context not as communicating or expressing pre-existing meaning but as positioning subjects changes the whole basis of creating meaning. 


\section{References:}

1. Amosova, N.N. (1968) English Contextology. Leningrad: LOLGU.

2. Arnold, I.V. (1986) Lexicology of the Modern English Language. M.: Vyshaya Shkola.

3. Cruse, D.A. (1986) Lexical Semantics. Cambridge: CUP.

4. Cuyckens, H.; Zawada, B. (2001) Polysemy in Cognitive Linguistics. Selected Papers from the Fifth International Cognitive linguistics Conference, 1997. Amsterdam, Philadelphia: John Benjamin's.

5. Moon, R. (1987) The Analysis of Meaning. Chicago: University of Chicago Press.

6. Nerlich, N. (1992) Semantic Theories in Europe 1830-1930. From Etymology to Contextuality. Amsterdan, Philadelphia: John Benjamin's.

7. Salton \& Buckley (1991) Global Text Matching for Information Retrieval. pp. 1012 1015.

8. Taylor, J.R. (1989) Linguistic Categorization Prototypes in Linguistic Theory. Oxford, New York: OUP.

9. <mglukp.narod.ru/lexicology.doc $>$

10. $<$ http://cityref.ru/prosmotr/19537-0.htm>

\section{Source of Data:}

Galsworthy, J. The Apple Tree. <http://www.online-literature.com/john-galsworthy/five-tales/3/>

\section{คuqựưuunnıpjnıfip hưưuntpuunnıx}

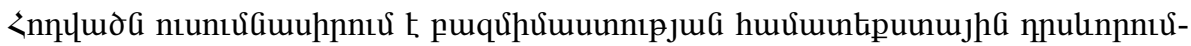

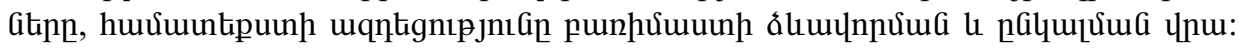

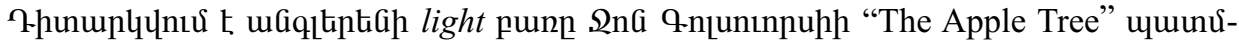

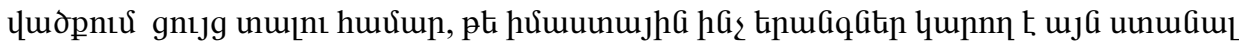

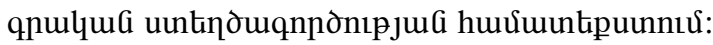

